Research Article

\title{
Modeling the Grain Import Trade: A Cointegration Analysis of China's Panel Data
}

\author{
Feng Zhao $\mathbb{D}$, Pingping Sun $\mathbb{D}$, and Jie Zhang $\mathbb{1}$ \\ School of Economics and Management, Shandong University of Science and Technology, Qingdao 266590, China \\ Correspondence should be addressed to Jie Zhang; zhangjie0371@sdust.edu.cn
}

Received 30 September 2021; Accepted 20 October 2021; Published 29 October 2021

Academic Editor: Daqing Gong

Copyright (c) 2021 Feng Zhao et al. This is an open access article distributed under the Creative Commons Attribution License, which permits unrestricted use, distribution, and reproduction in any medium, provided the original work is properly cited.

\begin{abstract}
In recent years, China has become the world's largest importer of grain, and scholars have particularly examined whether China's grain import trade presents this effect. By applying cointegration analysis to trade statistics panel data of China's wheat, corn, rice, and soybean production and imports from January 2016 to December 2019, this paper empirically tests for the existence of the great country effect in China's grain import trade. The results show that during the sample period, there is a long-term stable equilibrium relationship between the import volume, domestic price, and international price of the four major grains; the great country effect in the import trade of wheat and rice is not significant. The imports of corn and soybean present a great country effect to a certain extent in the short term; moreover, a change in the grain price in the international market does not lead to a change in China's grain import volume, which shows that the great country effect in China's grain import trade is distorted. Therefore, China should pay close attention to the impact of international factors on the fluctuation of its own food prices and enhance its ability to rationally utilize the international food market and international agricultural resources to ensure domestic food security.
\end{abstract}

\section{Introduction}

When a country has a large share of exports or imports of a certain commodity, it often has a significant influence on the international market price, which is called the "great country effect" in trade. Scholars have studied the influence of international grain prices on the domestic grain market and the grain trade in a country. For example, Dorosh [1] believed that if a country imported a single variety of grain, its grain production and grain trade would both be greatly affected by international grain prices. Chard [2] remarked, "the rise of international grain prices in recent years has caused the rise of the agricultural product prices of many countries, while the rapid rise of some agricultural product prices has disrupted the order of the import and export trade of international grain from an asymmetric perspective." Tweeten and Thompson [3] reported that the changes in domestic and foreign market prices were transmitted through trade, but the inconsistent domestic import and export market forces led to the asymmetry of the transmission effect of the international agricultural products in the country. Wright [4] found a correlation between the domestic grain market and the international grain market, but the influence was different for grain-producing countries and grain-consuming countries. Geoffrey [5] concluded that changes in international grain prices would greatly influence the dependence of the grain trade on domestic grain imports and exports, but there was a limited effect on countries with little or no grain import and export trade.

In studies on the great country effect in the grain trade, the influence of grain imports and exports on international grain prices has been commonly analyzed by the correlation coefficient method, which seems to be too static to fit reality. Brown [6] first proposed the concept of the great country effect and predicted that the grain trade in China would rely heavily on imports in 2030, which would cause a considerable increase in international grain prices. In contrast, Lustig [7] found that the great country effect of the major grain-producing or grain-consuming countries in the grain import trade is not obvious. Masuda and Goldsmith [8] 
found that the great country effect in the grain import trade of the global major food producing and consuming countries is distorted, that is, the price in the world grain import and export trade is not based on the trade share of the producing and consuming countries but, rather, is manipulated and controlled by certain individuals. The share of grain exports and imports does not affect the international price of grain. Kathryn [9] reported that the impact of grainproducing or grain-consuming countries on international grain prices is based on certain preconditions. Adam [10] asserted that the grain trade policy of the major grainproducing countries would play a certain role in international grain prices and that a prudent grain trade policy would play a positive role in stabilizing the grain prices.

At present, there are few systematic studies on whether China plays a major role in trade in the world market, and the existing studies reach different conclusions. The question of whether there is a great country effect in China's food imports dates back to Brown's [6] work, "Who Will Feed China?" Brown believed that China's great food gap and strong purchasing power would buy out the world's food exports, threatening the food supply of the developing world, and world food security. Subsequently, academic circles have paid close attention to the problem of China's food imports. Koo [11] used the cost minimization model for analysis and concluded that China's food demand would stimulate the sustained growth of international food imports and drive up the international food price. Song et al. [12] developed a two-country partial equilibrium model and found that China had relatively large market power as a buyer in the soybean import trade and could depress the import price; therefore, they observed no great country effect. Wright [13] established a pricing-to-market model based on importers' pricing behavior and applied it to the study of China's grain import market forces. The results showed that China's grain imports and exports had little impact on international grain prices. Zhong Yu et al. [14] proposed that because China is a large country, its increasing grain imports would lead to a great country effect and a rise in prices in the international food market, which would automatically play a role in curbing imports. Zhao Feng et al. [15] believed that as a large country in the production and consumption of food and other agricultural products, China had a typical great country effect in the food import trade, and even a small amount of imports would lead to an increase in international market prices, which in turn would restrain the imports of food and other agricultural products.

Is there a great country effect in China's food import trade? If so, what is the extent of the impact? If not, what is the cause? At present, there is no clear conclusion on whether the great country effect exists in China's food import trade internationally. To address these issues, this paper uses the cointegration analysis method to test the specific statistical data of China's grain trade, verifies whether there is a great country effect in China's grain trade, and proposes several countermeasures according to the verification results.

The structure of the paper is shown in Figure 1. Section 1 is a literature review, introducing the relevant research results regarding the great country effect in grain trade. Section 2 analyzes the regional imbalance in world grain trade and the general situation of China's grain import trade, leading to the research content of this paper. Section 3 presents the research methods and principles and proposes the unit root test, Johansen cointegration test, VAR model, VAR impulse response, and other methods to discuss the principle of the great country effect in import trade. Section 4 is the empirical analysis, taking the import data of wheat, corn, rice, and soybean in China as the research object and using panel data from January 2016 to December 2019 to analyze the problem of a great country effect in China's grain import trade. Section 5 offers the conclusion of this paper on the basis of the empirical research.

\section{Regional Imbalance in World Grain Trade and the General Situation of China's Grain Import Trade}

2.1. Unbalanced Regional Structure of the World Food Trade. From the perspective of grain trade patterns, Asia, Europe, and North America are the areas with the largest grain trade in the world. In terms of the grain trade volume, the relative shares of the three continents are quite different. In 2019, the grain trade volumes of Asia, Europe, and North America were $67.6 \times 107 \mathrm{t}, 155.7 \times 107 \mathrm{t}$, and $120.6 \times 107 \mathrm{t}$, respectively, accounting for $28.0 \%, 26.1 \%$, and $20.2 \%$ of the global grain trade volume, and the total grain trade of the three regions accounted for more than $70 \%$ of the total global grain trade. Clearly, Asia, Europe, and North America occupy the dominant position in the grain trade, while the other three continents (South America, Africa, and Oceania) account for only $25.7 \%$ of the grain trade. It is not difficult to see that there is obvious spatial imbalance in the global grain trade pattern. To further explain the problem, it is necessary to conduct a comparative analysis of the net global grain trade pattern and per capita grain output. Over the period 1999 to 2019, comparative analysis based on the data of the United Nations Food and Agriculture Organization (FAO) shows that, whether at the beginning of the period (1999) or at the end of the period (2019), North America $(870.9 \mathrm{~kg}$ at the beginning of the period, $1153.6 \mathrm{~kg}$ at the end of the period), Europe $(421.9 \mathrm{~kg}$ at the beginning of the period, $553.1 \mathrm{~kg}$ at the end of the period), and Oceania $(588.7 \mathrm{~kg}$ at the beginning of the period, $593.1 \mathrm{~kg}$ at the end of the period) had per capita grain output that was much higher than the global average $(284.7 \mathrm{~kg}$ at the beginning of the period and $337.9 \mathrm{~kg}$ at the end of the period). In contrast, the per capita grain output in Asia, South America, and Africa was $193.5 \mathrm{~kg}, 209.4 \mathrm{~kg}$, and $160.1 \mathrm{~kg}$ at the beginning of the period and $278.6 \mathrm{~kg}, 276.7 \mathrm{~kg}$, and $159.3 \mathrm{~kg}$ at the end of the period, respectively, which were all lower than the global average. Therefore, the global grain trade pattern and production pattern exhibit a great imbalance. Our investigation revealed that the leading cause of this imbalance was population. Using ArcGIS software for analysis, the relevant results can more intuitively reveal the changes in the relationship between population factors and human-food comparison and the impact on the grain trade pattern on each continent, as shown in Figure 2. 


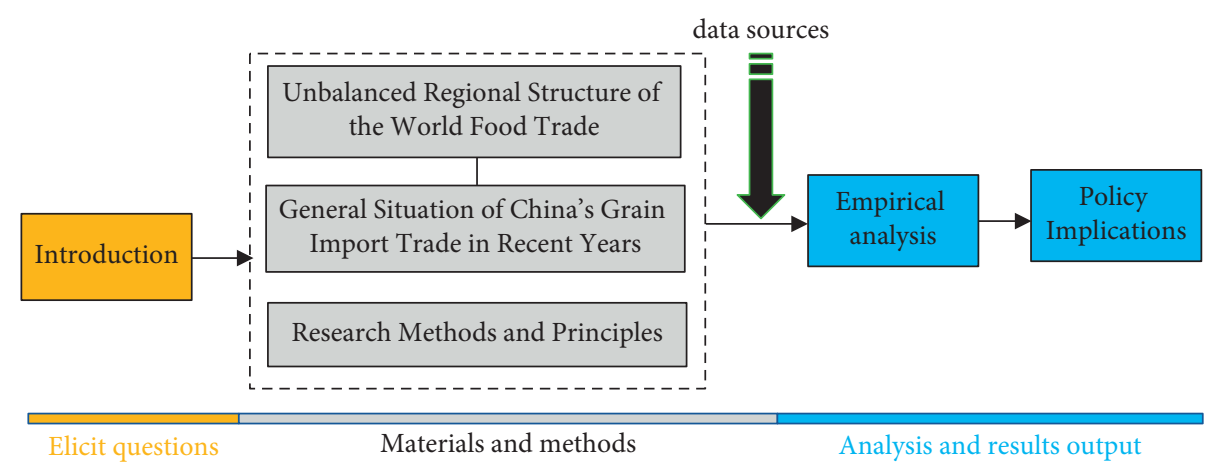

FIGURE 1: Research framework of the paper.
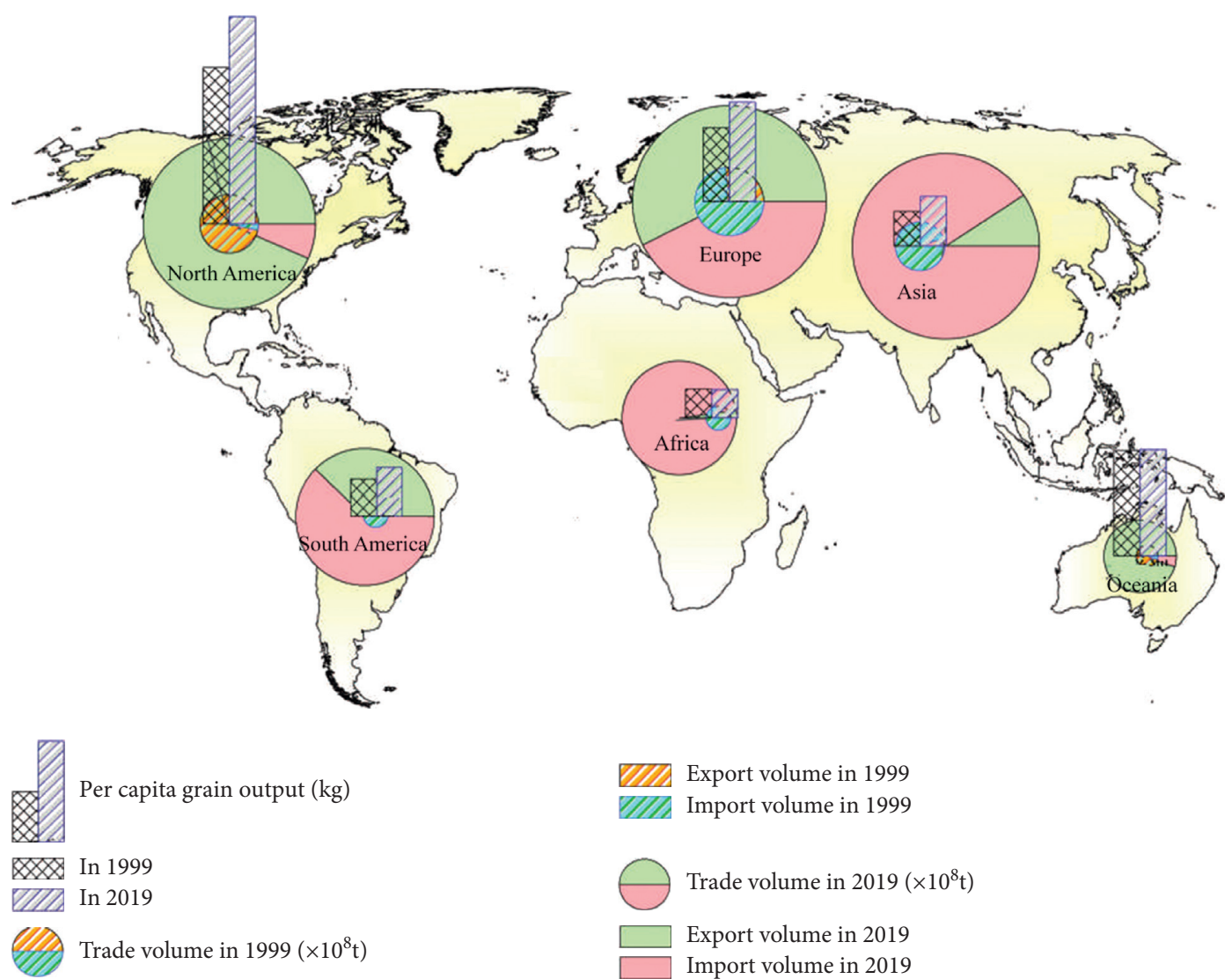

Figure 2: Comparison of global grain production trade and per capita patterns between 1999 and 2019.

2.2. General Situation of China's Grain Import Trade in Recent Years. Food security has always been an important issue in relation to the development of China's national economy and the living standards of the Chinese people. Food security includes many aspects, but the primary concern is maintaining the balance between the total grain supply and demand. When a country's domestic grain production cannot meet the consumer demand, it needs to rely on the international market supply, that is, imports of grain. It is precisely because of the growing domestic demand for grain consumption that China has become increasingly important as a net importer of grain. The rapid growth of grain imports has increased the dependence of China's domestic grain market on the international market and exposed China's grain trade to supply risk and price risk in the international grain market. Moreover, with the increase in the total population, the promotion of citizens' dietary structure and the increasing importance of industrial grain and feed grain, China's total grain demand will maintain rigid growth in the long term, leading to a tight balance of China's grain supply and demand under structural shortages. In the current situation of grain trade, China's grain imports show a sustained growth trend, and the country has shifted from a dominant net exporter to a constant net importer. The specific situations are shown in Figures 3 and 4 and Table 1. Therefore, this section takes wheat, barley, maize, rice, and soybean as examples to analyze the situation of China's grain import trade in the past 20 years. 


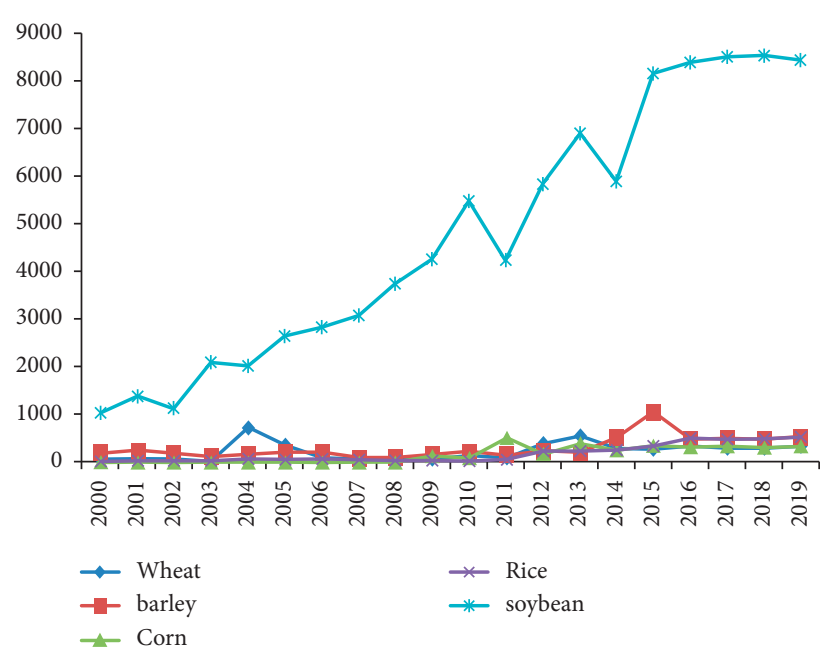

FIgURE 3: China's major grain imports (unit: 10,000 tons).

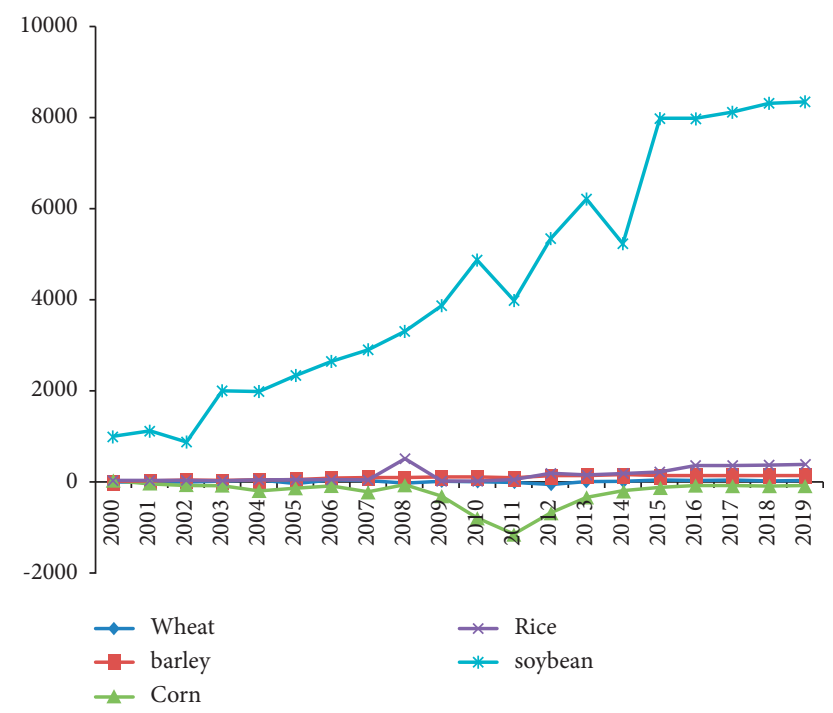

FIgURE 4: Net imports of major grains in China (unit: 10,000 tons).

According to Figure 3, China's wheat imports were 880,000 tons in 1997 and then substantially decreased but sharply increased to $7,233,200$ tons in 2004. The figure declined from 2005 to only 31,900 tons in 2008. After 2009, wheat imports constantly increased, reaching 5,431,400 tons in 2013, and then dropped to 3,004,000 tons in 2014. Except in 2002, 2003, 2006, 2007, and 2008, China has been a net importer of wheat. The volume has been rising since 2009, reaching 3,490,000 tons in 2018, with an annual increase of 390,000 tons and year-on-year growth of $12.6 \%$. According to Figure 4 and Table 1, China's wheat imports accounted for $0.84 \%$ of the global total wheat imports in 2000 and then decreased notably. The proportion began to rise in 2009 and increased to $5.11 \%$ in 2019 . In addition, according to the data of the United Nations Commodity Trade database, China was the fourth largest importer of wheat in the world in 2016.

According to Figure 3, China's barley import volume has been fluctuating since 2000. It was higher than 1 million tons in all years except 2007, reaching 2,335,300 tons in 2013 and substantially increasing to 5,003,000 tons in 2016. China has been a net importer of barley, with basic export volumes of less than 10,000 tons, since 2000. Net imports were higher than 1 million tons in all years except 2007, and China imported 6.82 million tons of barley in 2018, with an import value of US $\$ 1.69$ billion. China imported 5.929 million tons of barley in 2019, a decrease over the previous year. According to Figure 4 and Table 1, China's total barley imports have accounted for more than $5 \%$ of the global total barley imports since 2000. According to the data of the United Nations Commodity Trade database, China is a major barley importer and has been the second largest importer of barley in the world since 2009.

China's corn imports were 89,000 tons in 2000, then declined substantially, and remained below 90,000 tons between 2000 and 2009. Corn imports greatly increased to 1,572,400 tons in 2009 and further reached 5,194,400 tons in 2012. In 2013 and 2014, the volumes were reduced to $3,175,300$ tons and $1,296,000$ tons, respectively, and $4,790,000$ tons of corn were imported in 2019, an increase of 1.25 million tons or $35.43 \%$ year-on-year compared with 2018. China was a net importer of corn in 2000 and from 2009 to 2014, and the net imports were 2,580,000 tons in 2014. According to Figure 3 and Table 1, China's corn imports accounted for $1.5 \%$ of the global total corn imports in 2000 and then substantially decreased. The percentage was below 1.5\% between 2001 and 2009. The percentage increased continuously after 2008 , reaching $5.34 \%$ in 2012 , and falling to $4.53 \%$ in 2019 . According to the data of the United Nations Commodity Trade database, China was the eighth largest importer of corn in the world in 2016.

China's rice imports were 239,000 tons in 2000 and declined to below 800,000 tons from 2001 to 2011. Its rice imports substantially increased to 2,3441,00 tons in 2012 and further reached $3,260,000$ tons in 2019. China was a net importer of rice in 2000 and from 2010 to 2016, and the net imports were 2,160,800 tons in 2014. According to Figure 4 and Table 1, China's rice imports accounted for $1.15 \%$ of the global total rice imports in 2000 and then significantly decreased, and the percentage was below 3\% between 2001 
TABLE 1: The proportion of China's major grain imports in global main grain imports (unit: percent).

\begin{tabular}{lccccccccccc}
\hline Year & Wheat & Barley & Corn & Rice & Soybean & Year & Wheat & Barley & Corn & Rice & Soybean \\
\hline 2000 & 0.84 & 2.54 & 0.15 & 1.15 & 22.99 & 2010 & 0.93 & 9.68 & 1.63 & 1.39 & 59.51 \\
2001 & 0.69 & 0.37 & 0.04 & 1.35 & 25.54 & 2011 & 0.95 & 7.50 & 1.81 & 1.99 & 59.67 \\
2002 & 0.54 & 4.51 & 0.01 & 0.57 & 21.33 & 2012 & 2.86 & 10.30 & 5.34 & 8.50 & 64.17 \\
2003 & 0.42 & 7.49 & 0.01 & 0.73 & 33.38 & 2013 & 4.42 & 8.38 & 2.90 & 3.08 & 63.78 \\
2004 & 7.02 & 8.43 & 0.03 & 3.26 & 36.69 & 2014 & 4.32 & 20.50 & 2.69 & 9.64 & 63.24 \\
2005 & 3.19 & 9.40 & 0.05 & 2.09 & 39.44 & 2015 & 5.09 & 21.27 & 3.48 & 10.13 & 58.02 \\
2006 & 0.46 & 9.05 & 0.08 & 2.67 & 45.06 & 2016 & 5.13 & 20.89 & 4.51 & 12.76 & 57.92 \\
2007 & 0.07 & 4.16 & 0.04 & 1.71 & 44.10 & 2017 & 4.95 & 20.72 & 4.45 & 11.82 & 58.33 \\
2008 & 0.03 & 4.39 & 0.06 & 1.07 & 49.91 & 2018 & 5.03 & 21.03 & 4.62 & 11.62 & 58.17 \\
2009 & 0.77 & 8.33 & 0.11 & 1.41 & 56.48 & 2019 & 5.11 & 20.69 & 4.53 & 12.05 & 59.26 \\
\hline
\end{tabular}

Data sources: collated and calculated by the data from the United Nations Commodity Trade (UN COMTRADE) database from 2000 to 2019.

and 2011. It increased to $8.50 \%$ in 2012 and $12.05 \%$ in 2019 . According to the data from the United Nations Commodity Trade database, China has been the third largest importer of rice in the world since 2014.

China's soybean imports have continued to grow since 2000 , rising from 10,420,000 tons in 2000 to $71,399,000$ tons in 2014. China was a net exporter in the soybean trade in 1995. After China became a net importer in 1996, the volume continued to grow and reached 83,913,000 tons in 2016. According to Figure 4 and Table 1, China's soybean imports accounted for $22.99 \%$ of the global total soybean imports in 2000 and continued to increase thereafter. The percentage was $64.17 \%$ in 2012. It decreased in 2019 but still reached $59.26 \%$. According to the data of the United Nations Commodity Trade database, since 2000, China has been the largest importer of soybeans in the world.

Therefore, China's imports of wheat, barley, corn, rice, and soybean have remained high in recent years, especially as imports of soybean continue to grow. According to the data of the United Nations Commodity Trade database, China has been a net importer of the five major grain products since 2009, 1995, 2010, 2011, and 1996. China has become a major importer in the five major grain markets.

\section{Research Methods and Principles}

3.1. Unit Root (ADF) Test. Before testing the cointegration of the time series, the integration of the time series (nonstationary) and its integration order is first tested. According to the properties of time series integration and cointegration, it is possible for a cointegration relationship to exist only when the orders of two sequences are the same.

The paper uses the unit root (ADF) test to conduct the stationary test of the data sequence and determine the lag order by the SIC criterion [16]. The ADF test extends the DF test. The DF test assumes that the stochastic error term is subject to zero-mean, homoscedastic, and nonautocorrelative white noise sequences, while most of the economic sequence data in reality do not satisfy this hypothesis, which will affect the reliability of the DF test. To guarantee the white noise characteristic of the stochastic error term in the DF test, the ADF test is adopted.

The equation of the ADF test is defined as follows:

$$
\begin{aligned}
& \Delta y_{t}=\delta y_{t-1}+\sum_{i=1}^{m} \beta_{t} \Delta y_{t-i}+\varepsilon_{t}, \\
& \Delta y_{t}=\alpha+\delta y_{t-1}+\sum_{i=1}^{m} \beta_{t} \Delta y_{t-1}+\varepsilon_{t}, \\
& \Delta y_{t}=\alpha+\beta_{t}+\delta y_{t-1}+\sum_{i=1}^{m} \beta_{i} \Delta y_{t-1}+\varepsilon_{t},
\end{aligned}
$$

where $\beta_{t}$ in equation (3) is a time variable, reflecting the trend of the time series; equation (2) contains the intercept term $\alpha$, while equation (1) does not contain intercept terms or trend terms.

In the actual test, the null hypothesis is $H_{0}: \delta=0$; that is, there is a unit root. The testing process starts with model 3 , then model 2 , and model 1 , and stops when the null hypothesis is rejected (i.e., the original sequence that does not have a unit root is a stationary sequence). The $\mathrm{ADF}$ test principle is the same as that of the DF test with the difference that when models 1,2 , and 3 are tested, each model has a critical value table. When the DF test or ADF test is performed in Eviews software, the software automatically outputs the corresponding critical value, so the result can be judged directly according to the given critical value.

3.2. Johansen Cointegration Test Method. In the cointegration test, for the cointegration relationship between two or more variables, the Johansen maximum likelihood method is used for the test [17]. For multiple nonstationary time series, if a certain linear combination is stationary, there is a longterm stable equilibrium cointegration relationship between these variables. Generally, this relationship can be judged by the trace test and maximum eigenvalue [18].

3.2.1. Steps for the Johansen Cointegration Test Method. For $m$ time series $y_{t}=\left(y_{1 t}, y_{2 t}, \ldots, y_{m t}\right)^{\prime}(t=1,2, \ldots, T)$, determine whether a cointegration relationship exists between the $m$ economic indicators. Cointegration is defined as follows: 
Definition 1. Components of the $m$-dimension vector $y_{t}$ are referred to as $d, b$ order cointegration, denoted as $y_{t} \sim C I(d, b)$, if the following is satisfied:

(1) $y_{t} \sim I(d), y_{i t}$ is the component of $y_{t}$, and each component $y_{i t}$ satisfies $R(\Pi)=r$

(2) Nonvanishing vector $\beta$ exists, making $\beta^{\prime} y_{t} \sim I(d-b), 0<b \leq d$

If $y_{t}$ presents cointegration, vector quantity $\beta$ is also named the cointegrated vector. In general, supposing that a matrix constituted by the cointegrated vector of $y_{t}$ is $\Pi$, then the rank of matrix $\Pi$ is $R(\Pi)=r$, so $0 \leq r \leq k-1$.

The specific steps of the Johansen cointegration test method are as follows:

Step 1: use ordinary least squares (OLS) to estimate

$$
\Delta y_{t}=\sum_{j=1}^{p} \Gamma_{j} \Delta y_{t-j}+\varepsilon_{t}
$$

Each equation therein calculates the residual error and obtains the residual matrix $S_{0}$, which is an $(m \times t)$-order matrix.

Step 2: use OLS to estimate each equation $t$ in equation (5), calculate the residual error, and obtain the residual matrix $S_{1}$, which is also an $(m \times t)$-order matrix:

$$
y_{t-1}=\sum_{j=1}^{p} \Gamma_{j} \Delta y_{t-j}+\varepsilon_{t} .
$$

Step 3: structure the product matrix of the above residual matrix as follows:

$$
\left\{\begin{array}{l}
R_{00}=T^{-1} S_{0} S_{0}^{\prime}, \\
R_{01}=T^{-1} S_{0} S_{1}^{\prime} \\
R_{10}=T^{-1} S_{1} S_{0}^{\prime} \\
R_{11}=T^{-1} S_{1} S_{1}^{\prime}
\end{array}\right.
$$

Step 4: calculate the ordered eigenvalue and eigenvector of $R_{10} R_{00}^{-1} R_{01}$ related to $R_{11}$. The eigenvalue is defined as the solution of the characteristic equation:

$$
\left|\lambda R_{11}-R_{10} R_{00}^{-1} R_{01}\right|=0 .
$$

$1 \geq \lambda_{1} \geq \cdots \geq \lambda_{r} \geq \cdots \geq \lambda_{m} \geq 0, \quad$ composing diagonal matrix $\Lambda$; the matrix composed of the corresponding eigenvector is $B$, which is defined to be $R_{11} B \Lambda=R_{10} R_{00}^{-1} R_{01} B$, and $B$ is normalized by the following formula:

$$
B^{\prime} R_{11} B=I .
$$

Step 5: assume the likelihood function. When $\Pi$ is in the absence of restriction, the $m$ eigenvalue in equation (8) is reserved, and its log-likelihood function depends on $-T / 2 \sum_{i=1}^{m} \ln \left(1-\lambda_{i}\right)$, while for $R(\Pi)=r(0<r<m)$, the log-likelihood function is the function of $(-1 / 2) T \sum_{i=1}^{m} \ln \left(1-\lambda_{i}\right)$ with the greatest eigenvalue: $-T / 2 \sum_{i=1}^{m} \ln \left(1-\lambda_{i}\right)$.
3.2.2. Eigenvalue Trace Test (Trace Test). If the $r$-largest eigenvalue is given, the cointegration vector, for the remaining $m-r$ noncointegration combination, $\lambda_{r+1}, \ldots, \lambda_{m}$ should be zero, and the null hypothesis is $H_{r 0}$ : $\lambda_{r}>0, \lambda_{r-1}=0$, with $H_{r 1}$ denoted as having $m-r$ unit root, namely, presenting an $r$ cointegration relationship. The alternative hypothesis is unconstrained. The test statistics are as follows:

$$
\eta(m-r)=-T \sum_{i=r+1}^{m} \ln \left(1-\lambda_{i}\right), \quad r=0,1,2, m-1,
$$

where $\eta_{r}$ denotes rank test statistics and is subject to the Johansen distribution. When $r=0,1,2, \ldots, m-1$, a series of statistical values can be obtained: $\eta(m), \eta(m-1), \ldots$, $\eta(1)$.

Test the significance of a series of statistics successively until the occurrence of the first nonsignificant $\eta(m-r)$, which shows the existence of the $r$ cointegration vector. The $r$ cointegration vector is an exactly regularized eigenvector corresponding to the $r$-largest eigenvalue. Every step in the cointegration test belongs to the right single-ended test. The test statistic in equation (9) is called the eigenvalue trace statistic, so the above test is called the eigenvalue trace test.

3.2.3. Maximum Eigenvalue Test. The null hypothesis of a similar test is $H_{r 0}: \lambda_{r+1}=0$, denoted as having $m-r$ unit root, namely, an $r$-cointegration relationship. $H_{r 1}: \lambda_{r+1}>0$, indicating that the alternative hypothesis has an $m-r-1$ unit root. For test statistics based on the maximum eigenvalue $\left\{\lambda_{r}\right\}$, the formula is

$$
\varsigma(r-1)=-T \ln \left(1-\lambda_{r}\right), \quad r=0,1,2, \ldots, m-1 .
$$

These statistics are referred to as maximum eigenvalue statistics; therefore, this test is called the maximum eigenvalue test [19].

The test is performed from the bottom to the top; that is, the statistic $\varsigma(0)$ is tested until the appearance of the first nonsignificant $\varsigma(r-1)$, which demonstrates that an $(r-1)$ cointegrated vector exists and rejects the alternative hypothesis that the statistic has at least $r$ cointegrated vector. This $(r-1)$ cointegrated vector is a regularized eigenvector corresponding to the $(r-1)$-largest eigenvalue.

3.3. VAR Model and VAR Pulse Response. The vector autoregressive (VAR) model is a multivariate data analysis method that was first proposed by Phillips [20]. Not based on economic theory, the model directly considers the relationship among economic variables in a time series and uses the form of multiple equations synthesized to construct the model by regarding each endogenous variable in the system as a function of the lag value of all endogenous variables in the system. In each equation of the model, the endogenous variable regresses the lagged values of all the endogenous variables, and then the dynamic relationship of all endogenous variables is estimated and predicted; this has become one of the mainstream models of the macroeconomy. The general formula of the model is 


$$
Y_{t}=\alpha+\sum_{i=1}^{p} \beta_{i} Y_{t-i}+\varepsilon_{t},
$$

where $E\left(\varepsilon_{t}\right)=0, E\left(\varepsilon_{t}, Y_{t-i}\right)=0$, and $i=1,2, \ldots, p ; Y_{t}$ is a linearly stochastic process composed of $(m \times 1)$ vector quantity with stationary homoscedasticity, $\beta_{i}$ is a coefficient matrix of $(m \times m), Y_{t-i}$ is an $i$-order lagged variable of the $Y_{t}$ vector, and $\varepsilon_{t}$ is a $k$-dimension random error vector, where $\varepsilon_{t} \sim(0, \Sigma)$.

Any VAR model can be expressed as a process of the infinite order $M A(\infty)$ vector,

$$
\begin{gathered}
y_{t+s}=U_{t+s}+\Psi_{1} U_{t+s-1}+\Psi_{1} U_{t+s-2}+\cdots \\
\Psi_{s}=\frac{\partial Y_{t+s}}{\partial U_{t}}=\frac{\partial y_{i, t+s}}{\partial u_{j t}}, \quad s=1,2,3, \cdots
\end{gathered}
$$

The element of row $i$, column $j$, in $\Psi_{s}$ indicates the influence on $i$ endogenous variable under $y_{j t}$ in stage $t+s$ under the condition of maintaining other error terms unchanged, when the corresponding error term of the $j$ variable $y_{j t}, u_{j t}$ is the impulse by a unit at stage $t$.

Equation (13) is the impulse response function, which describes the response process of an impulse of $y_{i, t+s}$ as $u_{j, t}$ under the premise that other variables remain unchanged at stage $t$ and in previous stages. The impulse response function is able to capture the dynamic impact path of a variable's impulse factor on another variable, and variance decomposition can decompose the variance of a variable in the VAR system to each disturbing term. Thus, the variance decomposition provides the relative extent of the influence of each disturbing term on each variable in the VAR model.

3.4. Principle of the Great Country Effect in Import Trade. According to general price theory [21, 22], on the one hand, the rise in commodity prices in the international market will lead to an increase in the domestic production supply; on the other hand, the "crowding-out effect" of the price increase will reduce the domestic demand for this commodity. As a result, the combined effect of the two aspects will reduce the import of this commodity and further lower the international market price of the commodity; therefore, it can be said that the great country effect is not necessarily harmful to importing countries. The principle of the great country effect in import trade is shown in Figure 5.

Figure 5 shows the situation when a country has a great country effect in the import trade of a commodity. Suppose that the $D$ curve is the import demand curve of this commodity and the $S$ curve is the import supply curve, which is the export supply curve of the rest of the world to this country. For this country, before people's demand for this commodity increases, the import demand curve for the commodity is the $D_{1}$ curve, which intersects the import supply curve $S$ at point $M$. At this time, the country's import quantity and import price for this commodity are $Q_{1}$ and $P_{1}$, respectively. However, after the country's domestic demand for the commodity increases, the country's import demand for the commodity will increase accordingly, and the $D$ curve will move to the right and become

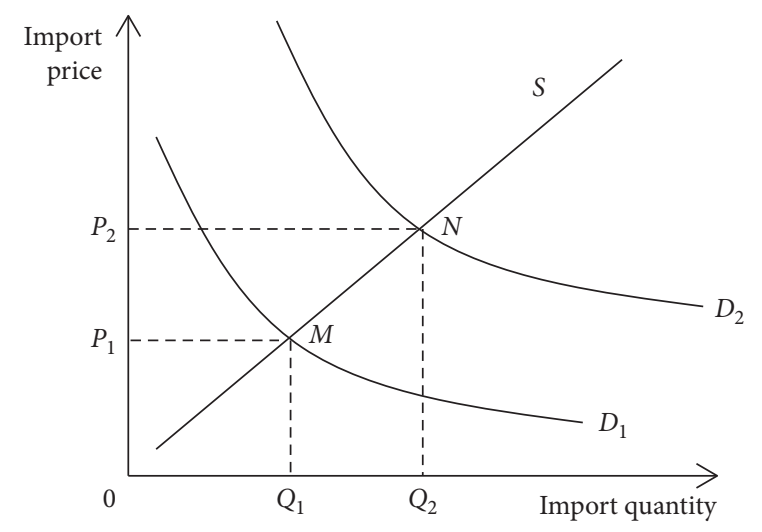

FIGURE 5: The principle of the great country effect in import trade.

curve $D_{2}$, which intersects curve $S$ at point $N$. At this time, the country's import quantity and import price for the commodity increase to $Q_{2}$ and $P_{2}$, respectively. Clearly, from Figure 5, when a country has a great country effect in the import trade of a commodity, its large import of the commodity will increase the international market price of the commodity. On the other hand, the rise in the international market prices to a certain extent will lead to an increase in domestic production and supply and a reduction in the domestic demand for the commodity, which will enable the country to reduce its import demand for the commodity and further reduce the international market price. As shown in Figure 5, the $D_{2}$ curve moves left to the $D_{1}$ curve; thus, the import quantity decreases from $Q_{2}$ to $Q_{1}$, and the international market price decreases from $P_{2}$ to $P_{1}$.

\section{Empirical Analysis}

4.1. Data Acquisition. The data on wheat, corn, rice, and soybean imports in China come from the China Customs database and are recorded as WheatIM, CornIM, RiceIM, and SoyIM in tons. The domestic price of wheat is the price of high-quality wheat in the Henan Zhengzhou Grain Wholesale Market (recorded as WheatDP), the domestic price of corn is the average wholesale price in the domestic corn growing area (recorded as CornDP), the domestic price of rice is the average wholesale price across China (recorded as RiceDP), and the domestic price of soybean is the factory price of Shandong domestic soybean (recorded as SoyDP). All the data come from the China Agricultural Information Network (https://www.agri.gov.cn/). The price unit of the four grains is Yuan/ton. The international wheat price is the FOB price of No. 1 US hard red winter wheat of the Gulf of Mexico (recorded as WheatIP), the international corn price is the FOB price of No. 2 US yellow corn of the Gulf of Mexico (recorded as CornIP), the international rice price is the price of Thailand 5\% white broken rice (recorded as RiceIP), and the international soybean price is the Chicago futures price of No. 2 US yellow soybean (recorded as SoyIP). All the data come from the food price monitoring database of the United Nations FAO (https://www.fao.orb/ giews/pricetool/). The international price of barley is indicated by the price of barley No. 1 in western Canada (denoted as BarleyIP), and the data come from the primary 
commodity price database of the International Monetary Fund (https://www.imf.org/external/np/res/commod/index. asp). To eliminate the effects of exchange rates on the comparability of the domestic price and international price of the four main grains, this paper employs the monthly mid-price of the RMB to USD exchange rate recorded by the People's Bank of China to adjust the international prices [23]. The adjusted price unit is Yuan/ton, and exchange rate data come from the website of the China Foreign Exchange Trade Center (https://www.Chinamoney.com.cn/). This paper performs natural logarithm processing on all variable data in the empirical analysis.

All data, including wheat, corn, rice, and soybean imports in China and domestic and international prices, are monthly data. To effectively investigate whether the great country effect exists in China's grain import trade, this paper locates the data sample period when the four main grain import shares rapidly increased or were raised to a higher level [24]. This is also a period when the four main grains were in a constant state of net imports. After the data availability was confirmed, the sample period for wheat, corn, rice, and soybean was set from January 2016 to December 2019. This paper provides descriptive statistics for all variable data samples by means of SPSS 17.0. As shown in Table 2, during the sample period, the minimum, maximum, and mean domestic monthly prices are noticeably higher than the international monthly price.

\subsection{Results Analysis and Discussion}

4.2.1. Unit Root Test. Most economic variables are nonstationary series with temporal change characteristics, so directly analyzing the interrelationship between those variables would result in spurious association and spurious regression [25]. Therefore, this paper adopts the ADF unit root test to test the stationary horizontal sequence and first-order difference sequence of wheat, corn, rice, and soybean imports and domestic and international prices. As Table 3 shows, at the $1 \%$ significance level, the variable horizontal sequence is nonstationary, while the first-order difference sequence is stationary. Thus, each variable is stationary integrated of order one, meeting the preconditions of the cointegration test.

4.2.2. Cointegration Test. To test whether a long-term stable interrelationship exists between wheat, corn, rice, and soybean imports and domestic and international prices, this paper employs the Johansen cointegration test method. According to the trace statistic value and $P$ value and the max-eigenstatistic value and $P$ value in Table 4 , at the $1 \%$ or $5 \%$ significance level, wheat, corn, rice, and soybean imports and domestic and international prices show cointegration relationships of $1,1,2$, and 1 , respectively, indicating a longterm stable balanced relationship.

4.2.3. Pulse Response Analysis. Pulse response analysis and variance decomposition analysis based on the VAR model aim to discuss in depth whether there is a great country effect in China's grain import trade. This paper employs the Monte Carlo [26] decomposition technique to perform pulse response analysis and divides the period into 20 periods. Then, it analyzes the dynamic change characteristics of the interrelationship between wheat, corn, rice, and soybean imports and domestic and international prices according to the pulse response function curve.

4.2.4. Variance Decomposition Analysis. To determine the relative importance and contributions of Chinese imports of wheat, corn, rice, and soybean and the lagged variables of domestic prices and international prices, as well as the proportions of each variable's impact on itself, Chinese imports and Chinese domestic prices given various international price changes, this paper conducts variance decomposition analysis.

As Figure 6 shows, for wheat, the shock of lnWheatIP to InWheatIM is continuously negative, and the shock degree is lower than -0.005 ; the shock of $\ln$ WheatIM to $\ln$ WheatIP is positive during period 2 and period 3, and the degree of each shock is 0.217 and 0.069 , respectively, but after period 4, the shock is continuously increasing and negative, reaching the highest level of -0.153 and thereafter gradually stabilizing to 0 . Considering the relationship between China's wheat imports and international prices, imports have recently increased, but the import share in world imports is not large. Therefore, the increase in Chinese wheat imports has little effect on international wheat prices; that is, there is no great country effect of Chinese wheat imports. The rise in the international price of wheat will have a strong inhibitory effect on China's wheat imports in the long run. This conclusion is consistent with the reality that Chinese wheat production is basically self-sufficient, and wheat is imported to make use of the international market to adjust domestic varieties. A shock of lnWheatDP to lnWheatIM is weak and positive during period 1 and period 2. From period 3, the response is continuously negative and lower than -0.007; during period 2 and period 3, a shock of $\ln$ WheatIM to $\ln$ WheatDP is negative, and from period 4 , the shock turns positive and begins to stabilize at 0.11 near period 8 . From the perspective of the relationship between Chinese wheat imports and international prices, during the sample period, domestic wheat prices are continuously and noticeably higher than international prices. Under the protection of the import tariff rate quota and wheat minimum purchase price policy implemented since 2010, wheat domestic prices increase in the short term. However, in the long run, the increase in wheat imports still has an inhibiting effect on domestic wheat prices, which does not support the maintenance of a reasonable rise in domestic wheat prices as domestic production costs continue to rise. The increase in domestic wheat prices will facilitate the development of wheat production and yield increase in the short term, thus leading to decreased imports. However, driven by the price discrepancy, wheat imports will further rise in the long run. 
TABLE 2: Statistical analysis results of the description variable.

\begin{tabular}{|c|c|c|c|c|c|c|c|c|}
\hline Variable & Unit & Sample size & Mini & Maxi & Average & Standard deviation & Skewness & Kurtosis \\
\hline WheatIM & Yuan/ton & 64 & 2275 & 1365082 & 241195 & 258437 & 2.0794 & 6.5161 \\
\hline WheatDP & Yuan/ton & 64 & 1949 & 3061 & 2355 & 478 & -0.1724 & -0.8566 \\
\hline WheatIP & Yuan/ton & 64 & 1132 & 2480 & 1697 & 326 & -0.3078 & -0.7275 \\
\hline CornIM & ton & 52 & 1048 & 787332 & 249051 & 268916 & 0.8132 & -0.6949 \\
\hline CornDP & Yuan/ton & 52 & 1653 & 2175 & 1980 & 154 & -0.7388 & -0.1437 \\
\hline CornIP & Yuan/ton & 52 & 1176 & 2283 & 1694 & 362 & -0.1317 & -1.5815 \\
\hline RiceIM & ton & 46 & 13725 & 517809 & 230186 & 89834 & 0.5163 & -0.1628 \\
\hline RiceDP & Yuan/ton & 46 & 3424 & 4028 & 3872 & 205 & -1.3093 & 1.8862 \\
\hline RiceIP & Yuan/ton & 46 & 2592 & 3874 & 3358 & 511 & -0.4139 & -1.4270 \\
\hline SoyIM & ton & 112 & 713280 & 5389036 & 3890412 & 1387445 & 0.6508 & -0.2733 \\
\hline SoyDP & Yuan/ton & 112 & 3156 & 6407 & 4431 & 739 & 0.0542 & -1.1373 \\
\hline SoyIP & Yuan/ton & 112 & 1898 & 4322 & 2783 & 654 & 0.5890 & -0.2724 \\
\hline
\end{tabular}

TABLE 3: Results of the ADF unit root test.

\begin{tabular}{|c|c|c|c|c|c|c|c|c|}
\hline \multirow{2}{*}{ Variable } & \multicolumn{4}{|c|}{ Horizontal sequence } & \multicolumn{4}{|c|}{ First-order difference array } \\
\hline & ADF statistic & Type & $1 \%$ critical value & Conclusion & ADF statistic & Type & $1 \%$ critical values & Conclusion \\
\hline lnWheatIM & -0.2415 & $0,0, L=0$ & -2.6131 & Nonstationary & -12.8329 & $0,0, L=4$ & -2.7123 & Stable \\
\hline lnWheatDP & -1.8396 & $C, T, L=0$ & -4.1577 & Nonstationary & -7.6793 & $C, T, L=0$ & -4.1685 & Stable \\
\hline lnWheatIP & -2.7132 & $C, T, L=1$ & -4.2395 & Nonstationary & -6.4351 & $C, T, L=0$ & -4.1685 & Stable \\
\hline $\operatorname{lnCornIM}$ & -2.8769 & $0,0, L=0$ & -4.5036 & Nonstationary & -7.3938 & $0,0, L=0$ & -4.3207 & Stable \\
\hline $\operatorname{lnCornDP}$ & -2.3581 & $C, T, L=2$ & -4.5194 & Nonstationary & -6.8145 & $C, T, L=1$ & -4.5426 & Stable \\
\hline $\operatorname{lnCornIP}$ & -1.6073 & $C, T, L=0$ & -4.5036 & Nonstationary & -5.9296 & $C, T, L=0$ & -3.8854 & Stable \\
\hline lnRiceIM & -2.7365 & $0,0, L=0$ & -4.2074 & Nonstationary & -7.827 & $0,0, L=0$ & -4.2361 & Stable \\
\hline $\operatorname{lnRiceDP}$ & -3.4902 & $C, T, L=0$ & -4.2074 & Nonstationary & -5.4412 & $C, T, L=0$ & -4.2361 & Stable \\
\hline lnRiceIP & -2.1136 & $C, T, L=1$ & -4.3579 & Nonstationary & -4.0837 & $C, T, L=0$ & -4.2361 & Stable \\
\hline lnSoyIM & 1.3074 & $0,0, L=5$ & -4.1055 & Nonstationary & -11.3874 & $0,0, L=0$ & -2.7662 & Stable \\
\hline $\ln$ SoyDP & -2.8690 & $C, T, L=1$ & -4.2738 & Nonstationary & -6.1036 & $C, T, L=0$ & -4.3276 & Stable \\
\hline $\operatorname{lnSoyIP}$ & -3.1527 & $C, T, L=1$ & -4.2712 & Nonstationary & -8.3975 & $C, T, L=1$ & -4.3155 & Stable \\
\hline
\end{tabular}

TABLE 4: Results of the Johansen cointegration test.

\begin{tabular}{|c|c|c|c|c|c|}
\hline Variety & $\begin{array}{c}\text { Original hypothesis (number of cointegration } \\
\text { relationships) }\end{array}$ & $\begin{array}{l}\text { Eigen } \\
\text { value }\end{array}$ & Trace statistics & $\begin{array}{l}\text { Max-Eigen } \\
\text { statistics }\end{array}$ & Conclusion \\
\hline \multirow{3}{*}{ Wheat } & e & 0.2307 & $\begin{array}{c}37.8166^{* * *} \\
(0.04123)\end{array}$ & $\begin{array}{c}25.8714^{* *} \\
(0.0237)\end{array}$ & \multirow{3}{*}{$\begin{array}{l}1 \text { cointegration } \\
\text { relation }\end{array}$} \\
\hline & $\leq 1$ & 0.08915 & $18.5474(0.2798)$ & $18.3078(0.41286)$ & \\
\hline & $\leq 2$ & 0.0626 & $3.9103(0.7765)$ & $3.9103(0.7765)$ & \\
\hline \multirow{3}{*}{ Corn } & 0 & 0.4182 & $35.8135^{* *}(0.0072)$ & $\begin{array}{l}25.8325^{* *} \\
(0.02459)\end{array}$ & \multirow{3}{*}{$\begin{array}{l}1 \text { cointegration } \\
\text { relation }\end{array}$} \\
\hline & $\leq 1$ & 0.1938 & $13.6192(0.1875)$ & $12.4193(0.1628)$ & \\
\hline & $\leq 2$ & 0.0223 & $0.7081(0.3980)$ & $0.7081(0.3980)$ & \\
\hline \multirow{3}{*}{ Rice } & 0 & 0.4180 & $\begin{array}{c}33.0189^{* * *} \\
(0.0052)\end{array}$ & $\begin{array}{c}18.4628^{* *} \\
(0.0043)\end{array}$ & \multirow{3}{*}{$\begin{array}{l}2 \text { cointegration } \\
\text { relation }\end{array}$} \\
\hline & $\leq 1$ & 0.2769 & $13.5837(0.0634)$ & $11.5175(0.0391)$ & \\
\hline & $\leq 2$ & 0.0024 & $0.0613(0.8921)$ & $0.0613(0.8921)$ & \\
\hline \multirow{3}{*}{ Soybean } & 0 & 0.3651 & $\begin{array}{c}69.3486^{* * *} \\
(\leq 0.001)\end{array}$ & $\begin{array}{c}53.8711^{* *} \\
(\leq 0.001)\end{array}$ & \multirow{3}{*}{$\begin{array}{l}1 \text { cointegration } \\
\text { relation }\end{array}$} \\
\hline & $\leq 1$ & 0.1435 & $22.5679(0.2176)$ & $12.8732(0.4269)$ & \\
\hline & $\leq 2$ & 0.0670 & $7.3935(0.3528)$ & $7.3935(0.3528)$ & \\
\hline
\end{tabular}

Note. The symbols ${ }^{* * *}$ and ${ }^{* *}$ indicate significance at the $1 \%$ and $5 \%$ levels, respectively; values in brackets after the statistical value are the $P$ values.

As Figure 7 shows, for corn, the shock of lnCornIP to lnCornIM gradually grows and has a continuous positive response from period 1, and it reaches the highest level of 0.032 in period 5 . Subsequently, it starts to continuously decrease. The shock of $\operatorname{lnCornIM}$ to $\operatorname{lnCornIP}$ is positive during period 2 and period 3, continuously negative from period 4 to period 9, and positive again in period 10 . Considering the relationship between Chinese corn imports and international prices, in recent years, Chinese corn imports have been at a high level. An increase in China's corn imports in the short term will cause the international price to rise to some degree, supporting the great country 

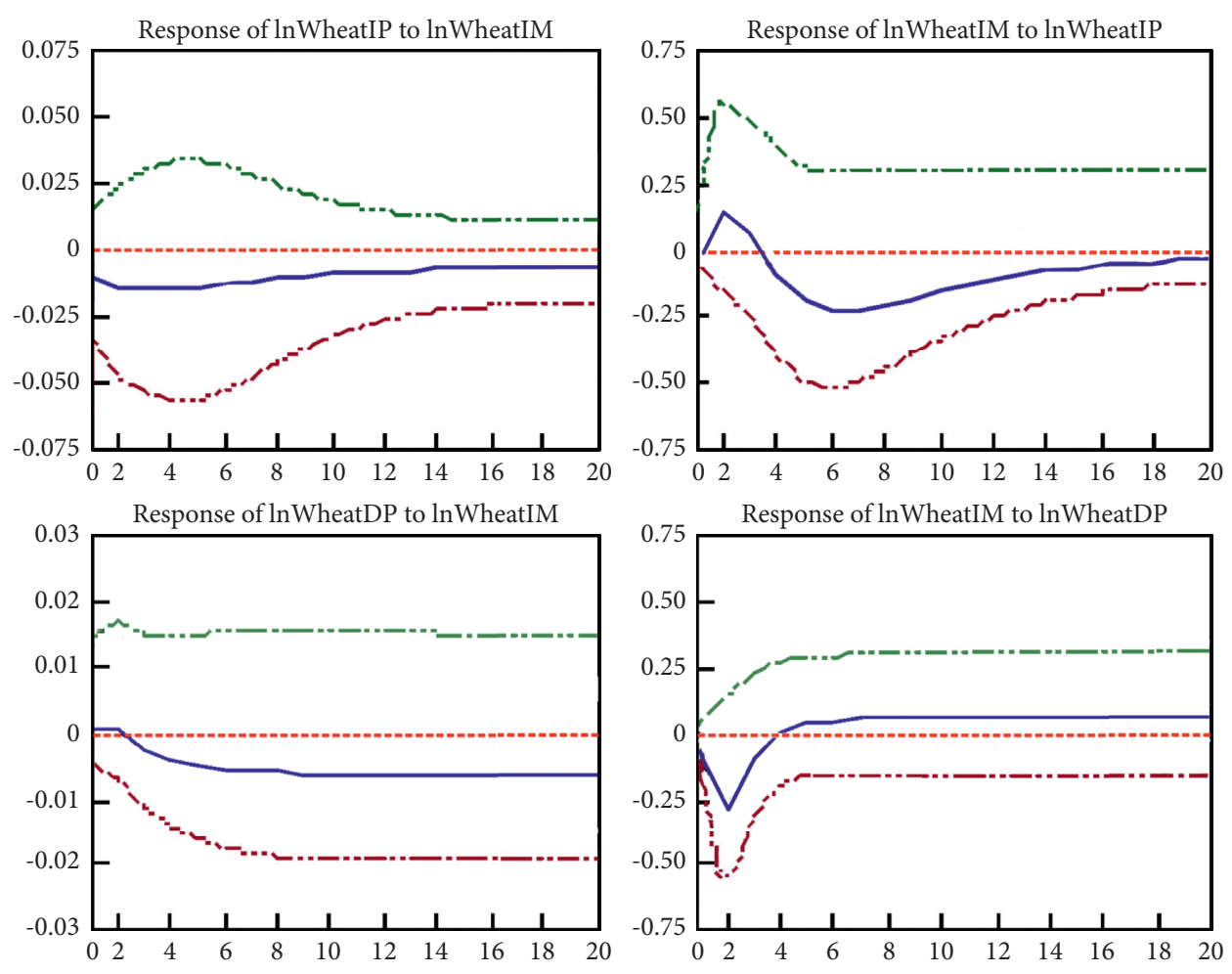

Figure 6: Pulse response analysis result for wheat.

effect, but the effect is weak in the long run. High international corn prices will stimulate domestic corn production, although the effect lags because of the long growing cycle, and corn imports increase in the short term. However, in the long run, corn imports will decrease as the domestic corn yield rises. The shock of $\operatorname{lnCornDP}$ to $\operatorname{lnCornIM}$ in period 2 is a weak and continuous positive response; the shock of $\ln$ CornIM to $\ln$ CornDP is negative from period 1 to period 3, but it starts to be positive in period 4 . In period 7 , it reaches the highest value of 0.331 and then gradually stabilizes to 0 . Considering the relationship between Chinese corn imports and international prices, under the protection of the import tariff-rate quota and support from the temporary policy for purchasing and stockpiling corn implemented since 2012, combined with the constantly low share of corn imports in China's corn gross supply, the increase in corn imports has a weak effect on domestic corn prices. The increasing price of domestic corn will stimulate domestic corn production development and yield increase, which will have an inhibiting effect on corn imports. However, since imported corn with a low cost advantage will become more competitive in price as domestic corn prices rise, and since the rapid development of domestic animal husbandry has led to an increasing need for corn feed in recent years, Chinese corn imports will still present noticeable growth in the long run.

As Figure 8 shows, for rice, the shock of $\ln$ RiceIP to lnRiceIM continuously weakens the negative response, and the shock degree is lower than 0.007 from period 1 ; after period 2, the shock of $\ln$ RiceIM to $\ln$ RiceIP presents a gradually increasing negative response. Regarding the interrelationship between Chinese rice imports and international rice prices, similar to the case for wheat, Chinese rice imports have increased in recent years, but the import share of gross imports in the world is relatively low. That is, an increase in Chinese rice imports has little effect on international rice prices, so there is no great country effect of Chinese rice imports. China's rice selfsufficiency rate has remained over $99 \%$ in recent years. Rice import and export trade aims to adjust domestic supply surplus and deficiency and thus relies little on the global market. Therefore, an international rice price rise will result in a noticeable decrease in Chinese rice imports in the long run. The shock of $\ln$ RiceDP to $\ln$ RiceIM is positive after period 1, and the shock degree continuously decreases until it stabilizes at 0 in period 3 . The shock of $\ln$ RiceIM to $\ln$ RiceDP is positive and increases gradually after period 2 . In period 4 , it reaches the highest value of 0.100 and then stabilizes to 0 . Regarding the interrelationship between Chinese rice imports and international rice prices, the share of Chinese rice imports in the gross supply is always small. Under the protection of the import tariff-rate quota and rice minimum purchase price policy implemented since 2010, the increase in Chinese rice imports has little effect on international rice prices. During the sample period, when the domestic rice price is continuously and noticeably higher than the international price, a further rise in the domestic rice price will make the international rice price more competitive, thus leading to an increase in Chinese rice imports.

As Figure 9 shows, for soybean, the shock of $\ln$ SoyIP to lnSoyIM continuously increases and is positive from 

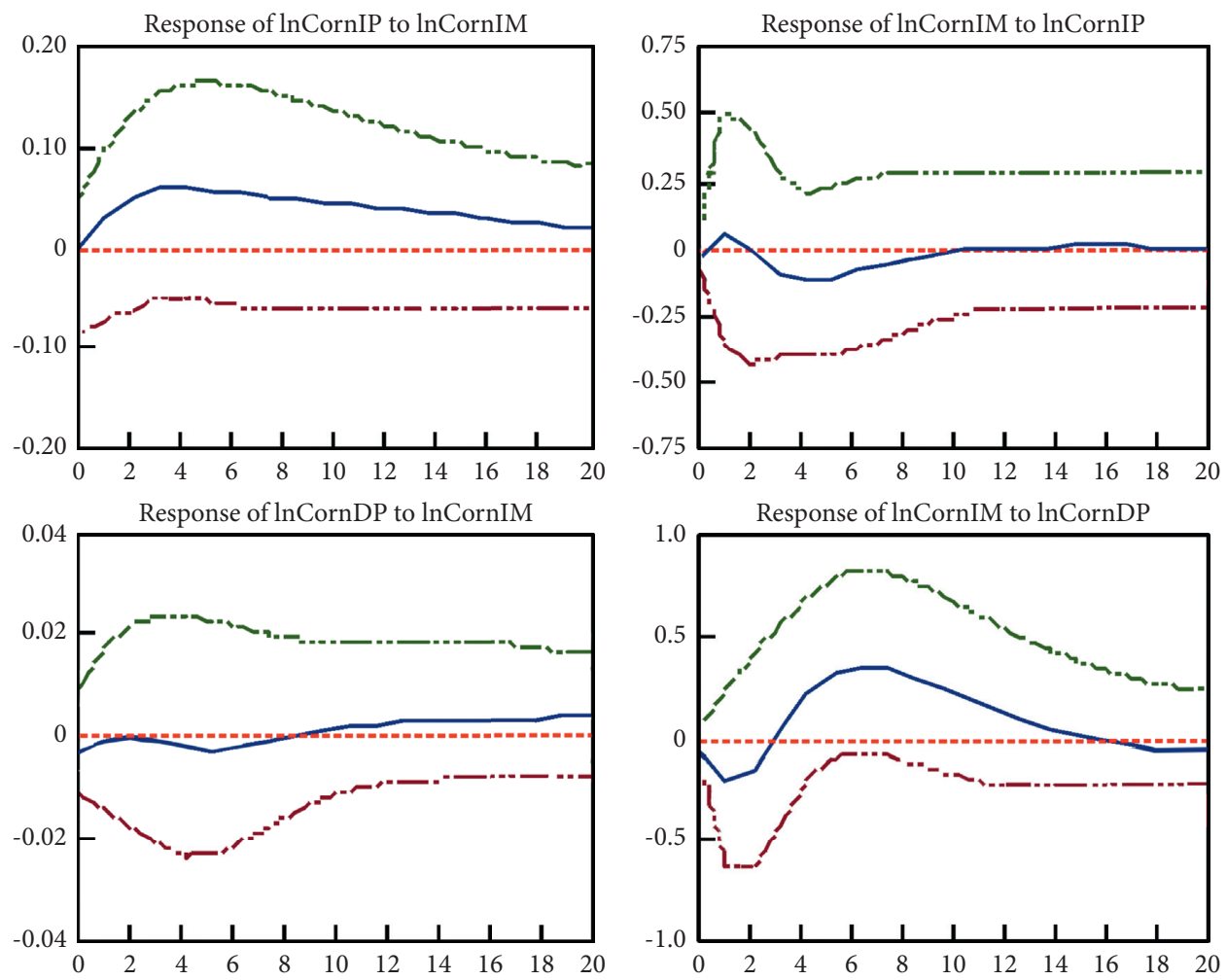

FIGURE 7: Pulse response analysis results for corn.

period 1. It reaches the highest value of 0.048 in period 5 , and then it starts to decease. The shock of InSoyIM to lnSoyIP is negative from period 2 and becomes continuously increasing and positive from period 3 . It reaches the highest value of 0.068 in period 12 and then begins to gradually decrease. Regarding the relationship between Chinese soybean imports and international prices, China has been the largest soybean importing country since 2000 , with its soybean imports making up more than $50 \%$ of the gross world imports, and the ratio has been increasing in recent years. Therefore, a change in Chinese soybean imports is likely to greatly influence international soybean prices; therefore, Chinese soybean imports present a great country effect. An increase in international soybean prices will result in a decrease in Chinese soybean imports in the short term. However, China's soybean supply has formed a trend of strong reliance on the global market, so China's soybean imports will rise again in the long run. The shock of $\ln$ SoyDP to $\ln$ SoyIM is weak and negative in period 1 and period 2, and the positive response increases at first and then decreases in period 3; the shock of $\ln$ SoyIM to $\ln$ SoyDP is increasingly positive from period 1, and it reaches the highest level of 0.048 in period 5 and then decreases gradually. During the sample period, the domestic soybean price was already noticeably and constantly higher than the international price. Therefore, an increase in domestic soybean prices will make foreign soybean prices more competitive, thus resulting in a further increase in Chinese soybean imports.
As Figure 10 shows, for wheat, the contribution rate of changes in lnWheatIP to changes in the international price of wheat is over $84 \%$ in period 20 , and the separate contribution rates of $\ln$ WheatIM and $\ln$ WheatDP impact are under $5 \%$ and $12 \%$, respectively. Chinese wheat imports have a weak impact on the international wheat price, which further proves that Chinese wheat imports do not have a great country effect. The contribution rate of changes in lnWheatIM to the wheat import quantity continuously decreases, falling from $93.42 \%$ in period 1 to $67.59 \%$ in period 20. The contribution rates of $\ln W$ heatDP and lnWheatIP are both 0 in period 1 , and then the rates increase constantly, reaching $9.72 \%$ and 8.31 , respectively, in period 20. China mainly plants and produces medium-gluten wheat. The yield of high-gluten wheat suitable for making bread and low-gluten wheat suitable for making biscuits is always low. To meet domestic needs, the import need for high-quality high-gluten wheat and low-gluten wheat from the global market is strong for the purpose of increasing variety. Therefore, although Chinese wheat imports are increasingly affected by international and domestic prices, China wheat imports remain at a stable, high level, and China has been a net importer of wheat since 2009 because import reliance has been formed to a certain extent.

As Figure 11 shows, for corn, the contribution rate of changes in lnCornIP to the international price of corn in period 20 decreases markedly, from $91.38 \%$ in period 1 to $46.59 \%$ in period 20 . The respective contribution rates of $\ln$ CornIM and $\ln$ CornDP, respectively, increase from $7.81 \%$ to $10.56 \%$ in period 1 to $21.33 \%$ and $43.70 \%$ in period 20 . 

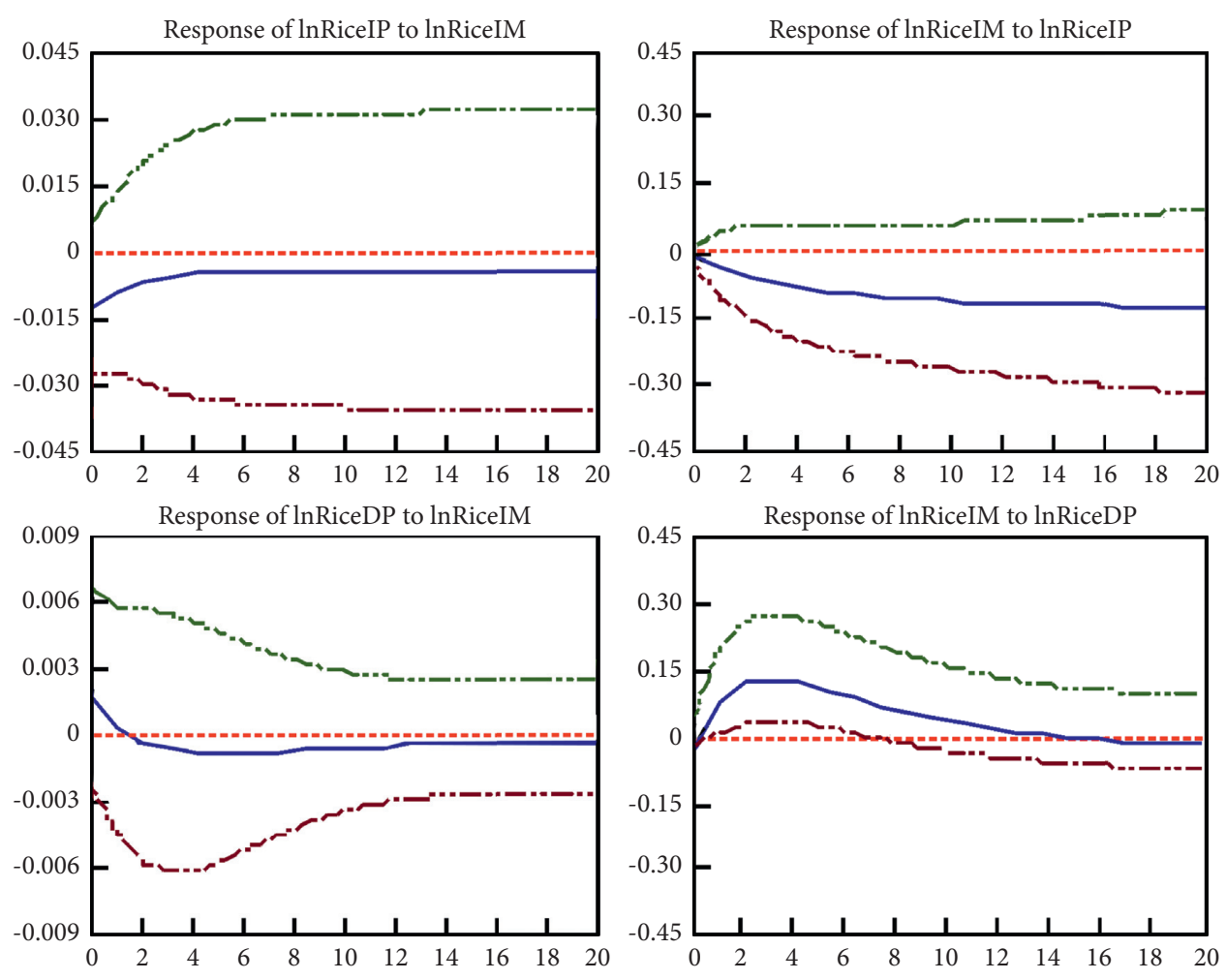

Figure 8: Pulse response analysis results for rice.
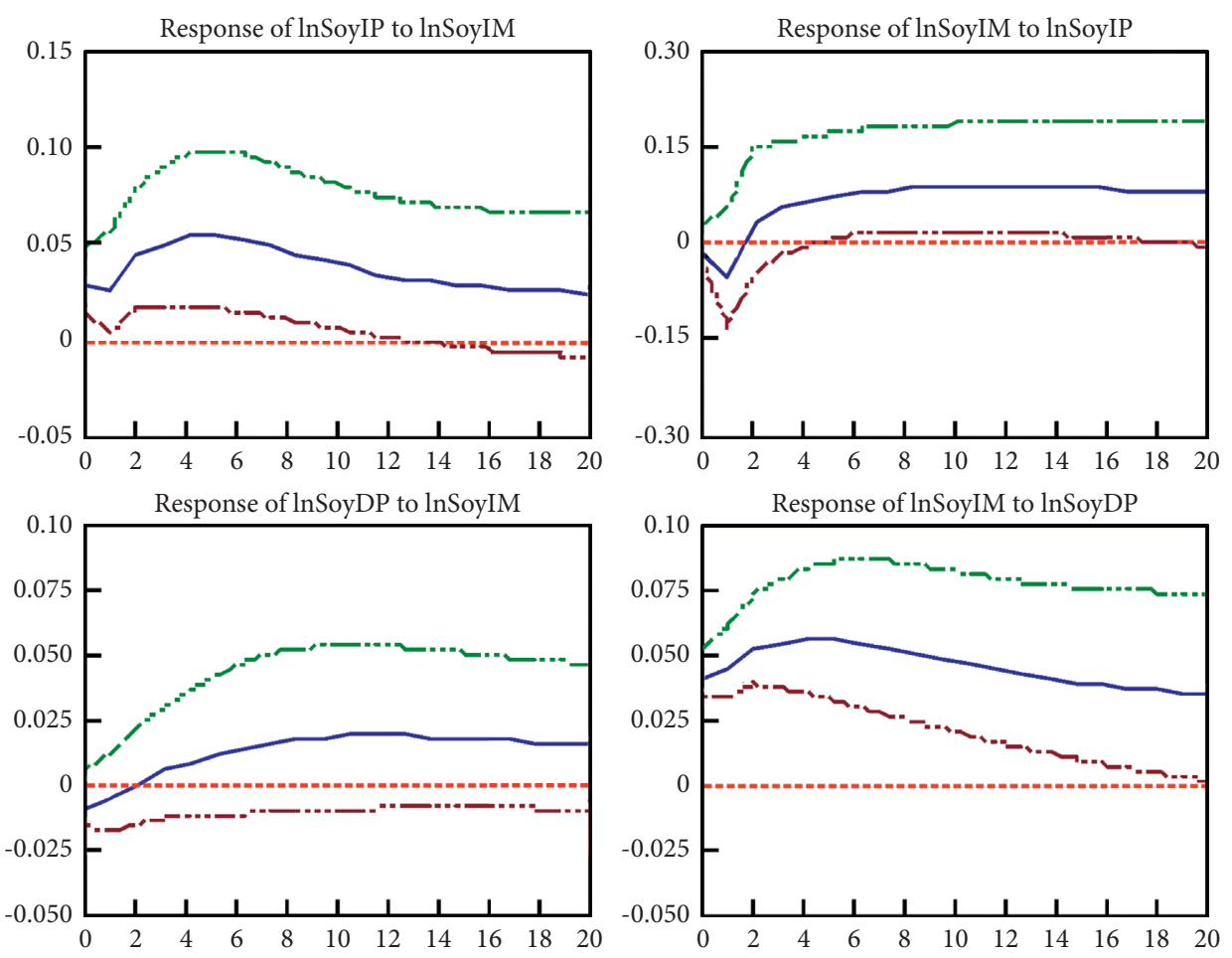

FIGURE 9: Pulse response analysis results for soybean.

With the constant and rapid increase in China's corn imports, changes in Chinese corn imports have an increasing influence on international corn prices, which further proves that Chinese corn imports present a great country effect. Moreover, the domestic corn market has a remarkably increasing influence on international corn prices. The 


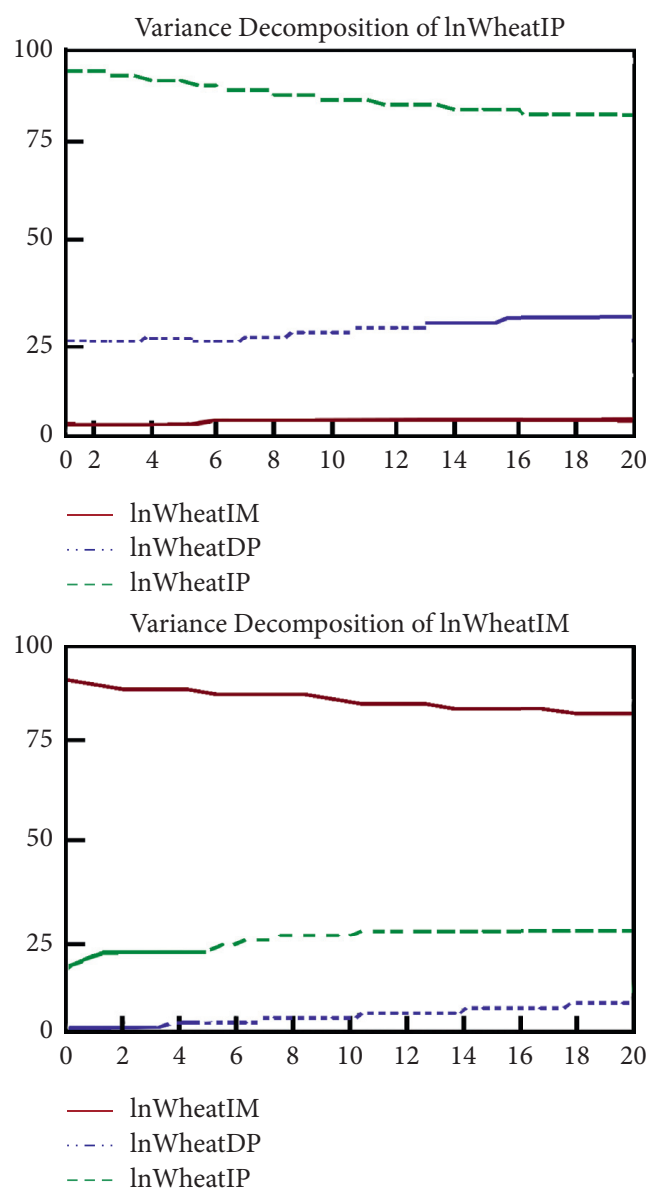

FIgURE 10: Variance decomposition analysis results for wheat.

contribution rate of changes in lnCornIM to the corn import quantity decreases from $100 \%$ in period 1 to $83.05 \%$ in period 20. The contribution rate of lnCornDP constantly increases to $17.93 \%$ in period 20 . The contribution rate of $\ln$ CornIP is under $5 \%$. In recent years, domestic corn prices have enjoyed fast yet steady growth and have been higher than international prices. Driven by the price discrepancy, domestic manufacturers' need to import low-price corn is constantly strong. Since 2010, China has been a net importer of corn, and its net imports have been steadily increasing.

As Figure 12 shows, for rice, the contribution rate of changes in lnRiceIP to the international price of rice increases and remains over $94 \%$ from period 10 . The contribution rate of $\ln$ RiceIM is $13.67 \%$ in period 1 , and it decreases constantly, falling below $4 \%$ in period 8 . The contribution rate of lnRiceDP is continuously under $2.5 \%$. Chinese rice imports have a very weak influence on international rice prices, indicating that there is no great country effect in Chinese rice imports. Domestic rice prices have a very small effect on international rice prices. The contribution rate of changes in InRiceIM to the import quantity decreases from $100 \%$ in period 1 to $73.66 \%$ in period 20 . The contribution rates of lnRiceDP and lnRiceIP are constantly increasing, with respective contribution rates of $23.24 \%$ and $27.53 \%$ in period 20 . Thus, domestic and international rice prices both have some influence on Chinese rice imports. In recent years, domestic rice prices have been constantly and substantially higher than international prices, and the price discrepancy has resulted in a strong import need. Since 2009, China has been a net importer in the rice trade.

As Figure 13 shows, for soybean, the contribution rate of changes in lnSoyIP to the international price of soybean decreases dramatically from $81.92 \%$ in period 1 to $53.19 \%$ in period 20 . The contribution rate of lnSoyIM increases from $22.85 \%$ in period 1 to $53.19 \%$ in period 20 , while the contribution rate of $\ln$ SoyDP is under $10 \%$ throughout the period. Therefore, Chinese soybean imports have a strong and constant influence on international soybean prices, which again proves that Chinese soybean imports present a great country effect. Domestic soybean prices have little influence on international prices. The contribution rate of changes in lnSoyIM to import quantity decreases from $92.71 \%$ in period 1 to $84.15 \%$ in period 20 . The contribution rate of $\ln$ SoyDP increases from $6.28 \%$ in period 1 to $16.37 \%$ in period 20 . The contribution of $\ln$ SoyIP increases from 0 in period 1 to $18.22 \%$ in period 6 and then constantly decreases to $14.53 \%$ in period 20. Therefore, international and domestic soybean prices both have effects on Chinese soybean imports. However, as China's soybean self-sufficiency rate decreases to a lower level, it develops a high 


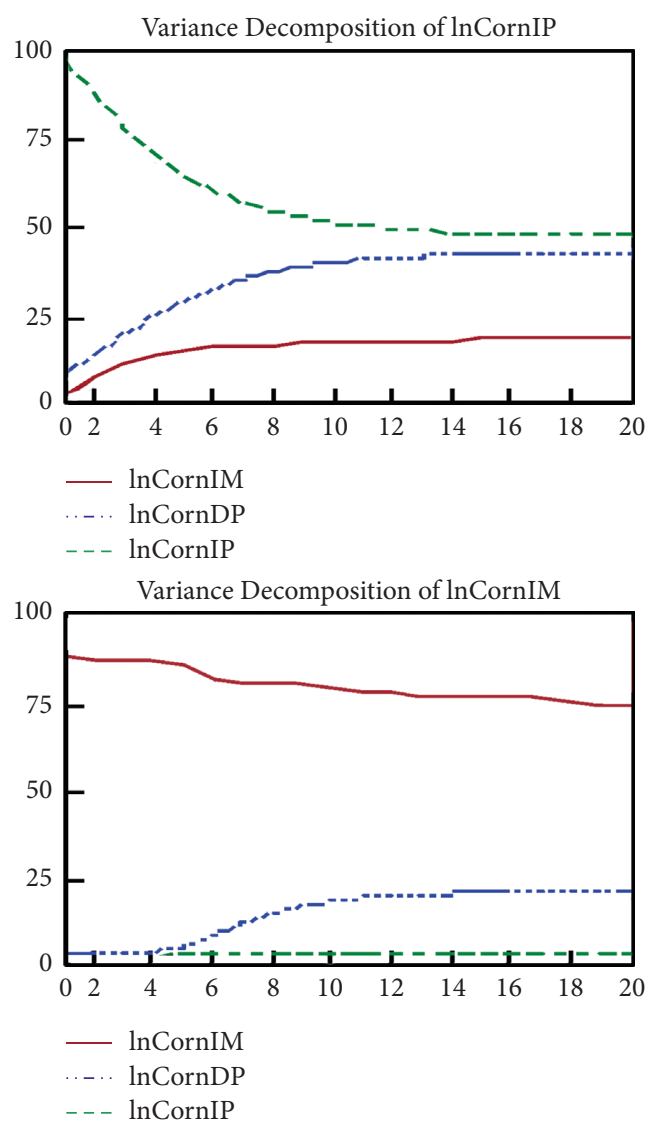

FIGURE 11: Variance decomposition analysis results for corn.

reliance on imports. Given its constantly growing need for soybeans, as the largest soybean importing country, China imports soybeans in constantly increasing quantities.

\section{Policy Implications}

As a major food consumption country in the world food market, China's grain import volume is an important factor that affects the changes in grain prices in the international market. However, the changes in food prices in the international market do not affect the changes in China's food imports. In other words, China does have a great country effect in the grain import trade, but this great country effect is distorted. Taking China as an example, if a country has a distorted great country effect in grain import trade, the following measures should be taken to solve this problem:

First, the construction of the grain production infrastructure should be strengthened to improve the production and supply capacity of the domestic grain. On the basis of consolidating the existing cultivated land area, the country should vigorously develop water conservation, strengthen investments in facilities and elements related to grain production, enhance the ability of domestic agriculture to cope with various natural disasters, stabilize and gradually improve the production capacity and output of grain, reduce the import volume of grain, and reduce dependence on the international food market.

Second, transnational cooperation in grain production should be carried out to reduce and avoid trade links in the international grain market. Taking the level of enterprises and government as guidance, China should engage in cooperation in grain production and the deep processing of grain with the countries with rich land resources and avoid the manipulation of the international grain market by international monopoly enterprises and organizations. Moreover, China should reduce the impact of fluctuations in international market trading links on its food import trade and food security, maintain the country's arable land security and ecological security, and deepen economic and trade ties with food cooperation countries.

Third, the international trade rules system should be used to safeguard the fair regulation of the domestic food import trade. China's grain import volume occupies a large part of the international grain market, and the import volume of most grain varieties occupies the first position in the world. However, China's grain import trade is in a subordinate position, and there is an obvious distortion phenomenon of the great country effect, which is not in line with the economic rationality and harms China's grain market. Therefore, China should make full 


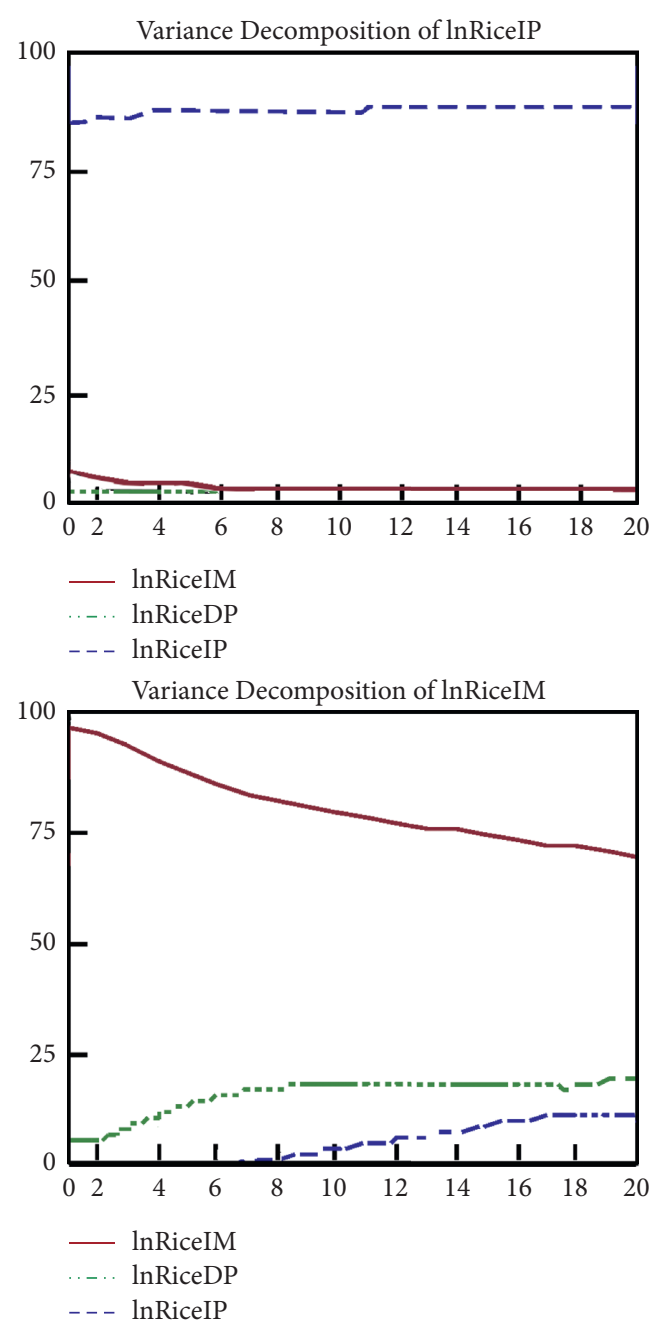

Figure 12: Variance decomposition analysis results for rice.

use of the fairness and reciprocity clauses in the international trading system to safeguard the legitimate rights and fair status of China's food trade.

Fourth, China should take advantage of its status as a great power in food trade and respond vigorously to monopolization and speculation in international food trade. Based on China's status as a large player in grain import trade and its huge demand for grain, to break the monopolization and speculation in the international grain trade, China should fully leverage its huge grain import scale, weaken the manipulation and speculation of monopoly enterprises and organizations on the international market food price, guide them to accept fair and reasonable trading rules, invest in international food monopoly enterprises or purchase their shares, engage in the internal management of international food monopoly organizations, increase its voice in the discourse on food trade, and promote the healthy development of China's food import trade.
Fifth, the national grain reserve system should be improved to establish and improve food security early warning and emergency systems. National food security is not only an economic problem but also a structural problem. To further improve the national grain reserve system, on the one hand, it is necessary to reasonably determine the proportion of local grain reserves and gradually increase the proportion of central grain reserves to establish the central grain reserve as the main body, assisted by provincial reserves. In addition, China should continue to optimize the layout and variety structure of the grain reserve, coordinate the production layout of major grain varieties, the scale of sales areas and market demand, and optimize the logistics system to more closely coordinate production areas and sales areas. Finally, it is important to plan the regional layout of national grain reserves for production and consumption to form a food security reserve and transportation network with responsive grain scheduling, flexible throughput, energy-saving measures and waste reduction, and guaranteed supply. 

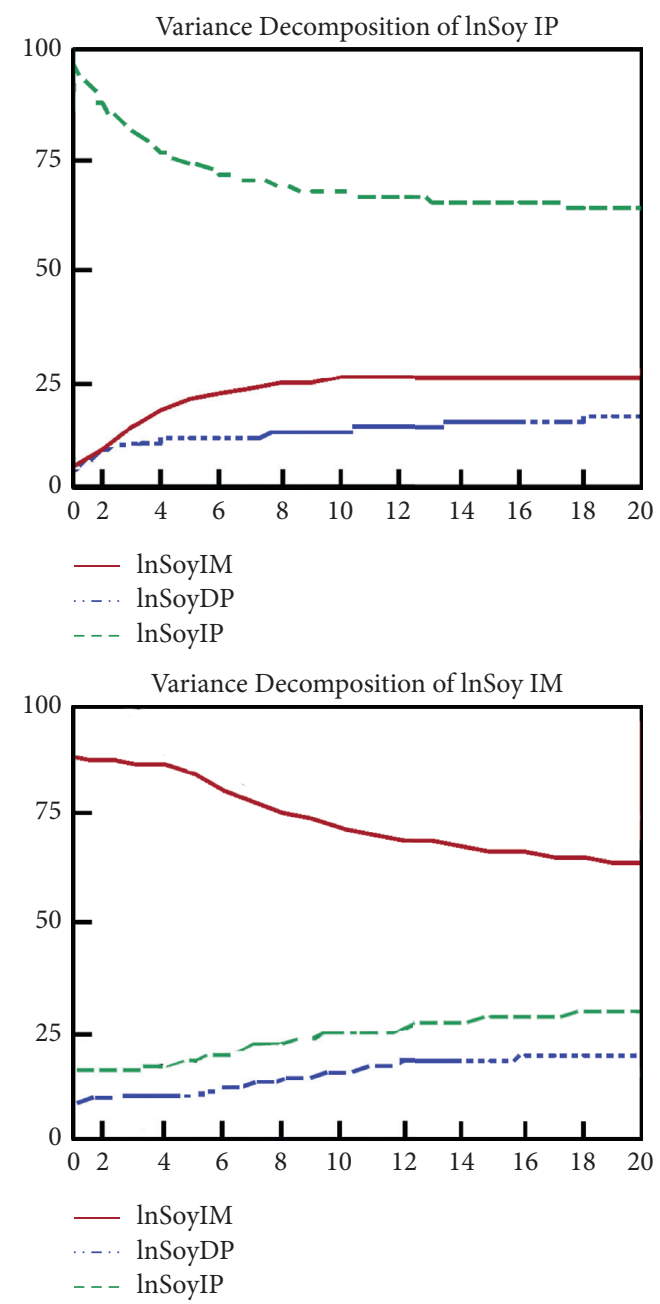

FIGURE 13: Variance decomposition analysis results for soybean.

\section{Data Availability}

The data used to support the findings of this study are available from the corresponding author upon request.

\section{Conflicts of Interest}

The authors declare that there are no conflicts of interest regarding the publication of this paper.

\section{Acknowledgments}

This research was supported by the general program of the Natural Science Foundation of Shandong Province (No. ZR2019MG021) and the Key Projects of the National Statistical Scientific Research Plan (No. 2019LZ19). The research was also supported by the Social Science Planning (Dominant Discipline) Research Project of Shandong Province (No. 19BYSJ19).

\section{References}

[1] P. A. Dorosh, "Trade liberalization and national food security: rice trade between Bangladesh and India," World Development, vol. 29, no. 4, pp. 673-689, 2001.

[2] R. Chard, Government Intervention in Food Grain Markets in the New Context, National Centre for Agricultural Economics and Policy Research, New Delhi, India, 2003.

[3] L. Tweeten and S. R. Thompson, "Long-term global agricultural output supply-demand balance and real farm and food prices," Farm Policy Journal, vol. 6, no. 1, pp. 1-16, 2009.

[4] B. D. Wright, "The economics of grain price volatility," Applied Economic Perspectives and Policy, vol. 33, no. 1, pp. 32-58, 2011.

[5] L. Geoffrey, R. Carol, and L. Kristen, "Food security in Australia in an era of neoliberalism, productivism and climate change," Journal of Rural Studies, vol. 53, no. 8, pp. 1-10, 2012.

[6] R. Brown lester, "Who will feed China?" Wake-up Call for a Small Planet, pp. 15-26, W. W. Norton \& Company, New York, NY, USA, 1995.

[7] N. Lustig, "Coping with rising food prices: policy dilemmas in the developing world," Center for Global Development Working Paper, vol. 64, no. 8, pp. 327-356, 2009.

[8] T. Masuda and P. D. Goldsmith, "World soybean production: harvested, yield, and long-term projections," International Food and Agribusiness Management Review, vol. 12, no. 4, pp. 143-162, 2009.

[9] K. T. Morrison, T. A. Nelson, and A. S. Ostry, "Methods for mapping local food production capacity from agricultural statistics," Agricultural Systems, vol. 104, no. 5, pp. 491-499, 2011.

[10] A. E. Ahmed, S. M. Abdelsalam, and K. H. A. Siddig, "Do grain reserves necessarily contribute to prices stability and food security in Sudan? An assessment," Journal of the Saudi Society of Agricultural Sciences, vol. 11, no. 2, pp. 143-148, 2012.

[11] Koo, "The impacts of China's accession into the WTO on the U.S. wheat industry," Agricultural Economics Report, vol. 40, no. 7, pp. 1-18, 2000.

[12] M. Song and X. Reed, "Competitive analysis and market power of China's soybean import market," International Food and Agribusiness Management Review, vol. 36, no. 12, pp. 21-42, 2009.

[13] Wright, "International grain reserves and other instruments to address volatility in grain markets," The World Bank Reserve Observer, vol. 62, no. 2, pp. 1-39, 2012.

[14] Y. Zhong, B. Chen, L. Wang, and X. Y. Lv, "Evidence of the "large country effect" from empirical study of impacts by China's grain imports on international grain price-a case study of staple food," China Agricultural University Journal of Social Sciences Edition, vol. 32, no. 6, pp. 119-126, 2015.

[15] F. Zhao, X. F. Song, and J. Zhang, "Research on Imbalance of agricultural industry chain and "big country effect" of grain import trade testing and "going out" strategy," Chinese Journal of Xinjiang Social Science, vol. 3, no. 3, pp. 38-46, 2018.

[16] X. X. Zuo, "ADF unit root test with high order trend term," The Journal of Quantitative and Technical Economics, vol. 35, no. 1, pp. 152-169, 2019.

[17] S. Johansen, "The role of the constant and linear terms in cointegration analysis of non-stationary variables," Econometric Reviews, vol. 13, no. 4, pp. 205-229, 1994.

[18] R. F. Engle and C. W. J. Granger, "Co-integration and error correction: representation, estimation, and testing," Econometrica, vol. 55, no. 2, pp. 251-276, 1987.

[19] S. Johansen, "Statistical analysis of co-integration vectors," Journal of Economic Dynamics and Control, vol. 33, no. 12, pp. 231-254, 1988. 
[20] P. C. B. Phillips, "Understanding spurious regressions in econometrics," Journal of Econometrics, vol. 33, no. 5, pp. 311-340, 1986.

[21] F. Q. Zhu, "The pricing mechanism in the market under uncertainty: a reflection on neo-classical price theory based on the analysis framework of psychology and power," The Journal of Finance and Economics, vol. 44, no. 5, pp. 61-82, 2018.

[22] B. X. Li and Z. Cui, "Tensor analysis of the price theory: a neoclassical alternative framework," The Chinese Journal of Contemporary Economic Research, vol. 25, no. 2, pp. 5-15, 2019.

[23] J. Yoon and S. Joung, "Examining purchase intention of ecofriendly products: a comparative study," Journal of System and Management Sciences, vol. 9, no. 3, pp. 123-135, 2019.

[24] K. Vladimir, "Directional splines for economic analytics," Economic Computation and Economic Cybernetics Studies and Research, vol. 54, no. 3, pp. 129-144, 2020.

[25] X. Y. Dong and S. G. Zhao, "Study on the nonlinear relationship between China's economic growth and leveragebased on the panel data threshold regression analysis of manufacturing industry," The Chinese Journal of Systems Engineering Theory and Practice, vol. 40, no. 2, pp. 343-354, 2020.

[26] G. T. Chi, Y. J. Zhang, and S. J. Ding, "Loan portfolio selection model based on power spectral risk measure and Monte Carlo simulation," Chinese Journal of Management Science, vol. 27, no. 9, pp. 1-14, 2019. 